\title{
Antisemitismus in der katholischen Tageszeitung Hrvatski Glas im Jahr 1941
}

\author{
Anti-Semitism in the Catholic daily \\ newspaper Hrvatski Glas in 1941 \\ Antisemitizem v katoliškem dnevniku \\ Hrvatski Glas v letu 1941
}

Zusammenfassung: Die Abhandlung untersucht das Verhältnis zwischen der katholischen Kirche und der jüdischen Gemeinde in einer für Juden besonders wichtigen und traumatischen Zeit wie die Gründung und Konsolidierung der neuen Ustascha-Regierung im Unabhängigen Staat Kroatien im Jahre 1941. Da die katholische Tageszeitung Hrvatski Glas (Kroatische Stimme) von Januar bis Ende August 1941 regelmäßig aufgelegt wurde, wird man durch die Analyse von Zeitungsinhalten nach Antworten auf die folgenden Fragen suchen: Wie geht diese katholische Zeitung mit der Judenfrage um, die mit der Gründung des Unabhängigen Staates Kroatien besonders relevant wurde? Ist der Antisemitismus, und in welchem Maße, in dieser Zeitung vorhanden? Ist er etwas Auferlegtes oder kann man auf eine ungezwungene Zusammenarbeit zwischen der Zeitungsredaktion und den Ustascha-Behörden schließen?

Mit der komparativen Analyse wird man den antisemitischen Inhalt von Hrvatski Glas mit anderen katholischen Medien vergleichen, um Übereinstimmungen und Unterschiede zu diesem Thema in einem breiteren Kontext festzustellen. Betrachtet man die gesamte katholische Presse auf dem Gebiet des Unabhängigen Staates Kroatien mit dem Schwerpunkt Antisemitismus, so kann man eine Vielzahl möglicher Reaktionen auf den offiziellen Antisemitismus der Ustascha-Behörden feststellen. Diese Untersuchung zeigt, dass Hrvatski Glas zu dem Kreis der Zeitungen gehörte, die die antisemitische Politik der Ustascha-Regierung aktiv und vorbehaltlos unterstützt hat.

Schlüsselwörter: Antisemitismus, Katholische Tageszeitung Hrvatski Glas, Unabhängiger Staat Kroatien, Ustascha-Regierung

\begin{abstract}
The paper examines the relationship between the Catholic Church and the Jewish community in a particularly important and traumatic time for Jews, i.e. during the establishment and consolidation of the new Ustasha government in the Independent State of Croatia in 1941. As the Catholic daily newspaper Hrvatski Glas (Croatian Voice) was published regularly from January to the end of August 1941, we will look for the answers to the following questions by analyzing newspaper contents: How does this Catholic newspaper deal with the Jewish question which became particularly relevant with the establishment of the Independent State of Croatia? Is anti-Semitism present in this newspaper and to what extent? Is it something imposed or can one conclude that the newspaper editorial team and the Ustasha authorities
\end{abstract}


worked together in an informal manner? The comparative analysis will compare the anti-Semitic content of Hrvatski Glas with other Catholic media in order to find similarities and differences on the subject in a broader context. If we look at anti-Semitism within the scope of the entire Catholic press in the area of the Independent State of Croatia, we can see a multitude of possible reactions to the official anti-Semitism of the Ustasha authorities. This investigation shows that Hrvatski Glas belonged to the circle of newspapers that actively and unreservedly supported the anti-Semitic policies of the Ustasha government.

Key Words: anti-Semitism, Catholic daily newspaper Hrvatski Glas, Independent State of Croatia; Ustasha government

Izvleček: Prispevek raziskuje odnos med Katoliško cerkvijo in judovsko skupnostjo v za Jude posebej pomembnem in travmatičnem času ustanavljanja in konsolidacije ustaškega režima v Neodvisni državi Hrvaški leta 1941. Na podlagi zapisov v katoliškem dnevniku Hrvatski glas, ki je od januarja do konca avgusta 1941 redno izhajal, bomo iskali odgovore na naslednja vprašanja: Kako ta katoliški časopis obravnava judovsko vprašanje, ki je postalo še posebej aktualno z ustanovitvijo Neodvisne države Hrvaške? Ali je antisemitizem prisoten v tem časopisu in v kolikšni meri? Gre pri tem za vsiljeno ali prostovoljno sodelovanje uredništva časopisa z ustaško oblastjo?

Sprimerjalnim pristopom bomo analizirali antisemitsko vsebino dnevnika Hrvatski Glas z drugimi katoliškimi mediji, da bi ugotovili podobnosti in razlike v širšem kontekstu. Ob primerjavi katoliškega tiska na območju Neodvisne države Hrvaške glede obravnave antisemitizma se kaže množični odziv na uradni antisemitizem ustaških oblasti. Raziskava ugotavlja, da je Hrvatski glas pripadal krogu časopisov, ki so aktivno in brez pridržkov podpirali antisemitsko politiko ustaške vlade.

Ključne besede: antisemitizem, katoliški dnevnik Hrvatski Glas, Neodvisna država Hrvaška, ustaška vlada

\section{Einleitung}

Die kroatische Geschichtsschreibung hat in jüngster Zeit größeres Interesse an der Erforschung der katholischen Presse im Allgemeinen ${ }^{1}$ als auch an derjenigen, die während des Unabhängigen Staates Kroatien ${ }^{2}$ aufgelegt wurde. Doch die Einstellung der katholischen Presse in Bezug auf den Antisemitismus wurde eher sporadisch angesprochen. ${ }^{3}$ Eine Ausnahme bildet das Buch U sjeni križa, samokresa i noža: katolički tisak u Nezavisnoj

1 Zum Thema katholische Presse in Kroatien bis zum Zweiten Weltkrieg kann man die folgende Literatur aufführen: Krišto, Jure. 2004. Hrvatski katolički pokret 1903.-1945. Zagreb: Glas Koncila; Tomić, Celestin. 2006. Moćpisane riječi. Zagreb: Glas Koncila; Buturac, Josip. 1989. Katolički dnevnik Hrvatska straža 1929-1941. Croatica Christiana Periodica 13: 141-201; Lončarević, Vladimir. 2005. Književno-kulturno značenje časopisa Hrvatska straža. Obnovljeni život 60: 55-71; usw.

2 Vgl. Josipović, Marko, ur. 1997. Život u službi riječi - Čedomil Čekada. Sarajevo: Studia Vrhbosnensia; Krišto, Jure. 2001. Sukob simbola. Politika, vjere i ideologije u Nezavisnoj Državi Hrvatskoj. Zagreb: Nakladni Zavod Globus; Macut, Petar. 2015. Katolički tisak o uspostavi Nezavisne Države Hrvatske 10. travnja 1941. godine. Časopis za suvremenu povijest 1: 81-102; usw.

3 Vgl. Prkačin, Zdenka. 2011. Katolički list o Židovima i judaizmu (od 1918. do 1941.). Slavonski Brod: Hrvatski institut za povijest - Podružnica za povijest Slavonije, Baranje i Srijema. 
Državi Hrvatskoj (Im Schatten des Kreuzes, Colts und Messer: Die katholische Presse im Unabhängigen Staat Kroatien) mit dem Kapitel Antisemitizam u katoličkom tisku (Antisemitismus in der katholischen Presse). (Macut 2016, 163-207) Dieses Kapitel bietet einen Überblick zu antisemitischen Beiträgen in den wichtigsten katholischen Zeitschriften, darunter auch in der Hrvatski Glas. Da dies nur ein Überblick war, mit dem der Autor beabsichtigt hat, das Thema Antisemitismus in der katholischen Presse im Unabhängigen Staat Kroatien im Allgemeinen darzustellen, werden in diesem Beitrag systematisch und umfassend antisemitische Inhalte in der letzten katholischen Tageszeitung Hrvatski Glas untersucht.

\section{Katholische Presse bis zur Gründung der Tageszeitung Hrvatski Glas}

Die katholische Kirche in Kroatien hat sehr früh die Bedeutung der Presse für ihre Tätigkeit erkannt. Ähnlich wie viele andere katholische Nationen erhielten die Kroaten Mitte des 19. Jahrhunderts ihre erste Zeitschrift Katolički list zagrebački (Zagreber katholisches Blatt). Bis zum Ende des 19. Jahrhunderts wurden ein Dutzend verschiedener katholischer Zeitschriften aufgelegt. Bereits 1904 besaß die katholische Kirche in Kroatien die Tageszeitung Hrvatstvo (Das Kroatentum). Das Blatt wurde von den Laien herausgegeben die der Kroatischen Partei der Rechte nahestanden. (Krišto 2004, 24-26) Wegen Meinungsverschiedenheiten zwischen den Bischöfen und der Redaktion wurde die Zusammenarbeit eingestellt und unter der Leitung des einflussreichen Bischofs Antun Mahnič wurde die Pius-Gesellschaft zur Förderung der katholischen Presse gegründet. Diese Gesellschaft hat die WochenzeitungJutro (Der Morgen) ins Leben gerufen, die zu einem Konkurrenten zum Blatt Hrvatstvo wurde. Andere katholische Tageszeitungen wurden jedoch erst im Dezember 1912 unter dem Namen Riječke novine herausgebracht. Zu Beginn des Ersten Weltkriegs wurde diese Tageszeitung verboten. Die Redaktion hat das Verbot umgegangen, indem sie von Rijeka nach Zagreb umzog und die Zeitung unter dem Namen Novine (Zeitung) auflegte. Nach dem Zerfall der österreichisch-ungarischen Monarchie hat die Tageszeitung Novine ihren Namen in Narodna politika (Volkspolitik) geändert. Nach mehreren Jahren ununterbrochener Auflage wurde die Narodna politika aufgrund verschiedener Konflikte innerhalb der Kroatischen katholischen Bewegung als Tageszeitung eingestellt und 
nur wöchentlich oder mehrmals pro Woche aufgelegt. Diese Situation dauerte bis 1929 an, als das Wochenblatt Narodna politika eingestellt wurde und die Tageszeitung Hrvatska straža (Kroatische Wache) ins Leben gerufen wurde, die längstlebige und einflussreichste katholische Tageszeitung in Kroatien, die von Juli 1929 bis Januar 1941 durchgehend aufgelegt wurde. Parallel zu dem Plan, die Hrvatska straža zu schließen, die sich zunehmend in die Politik eingemischt und die Aufgabe katholischer überparteilicher Zeitungen aus den Augen verloren hat, wollte die katholische Kirche, eine neue Tageszeitung herauszubringen, die den festgelegten Richtlinien entsprechen würde. Eine solche Tageszeitung sollte die Hrvatski Glas sein, die im Januar 1941 herausgebracht wurde. (Macut 2016, 15-33) Die Herausgabe einer neuen katholischen Tageszeitung mit einen neuen Namen hat jedoch keinen Bruch mit der Redaktion, den Journalisten und den langjährigen Mitarbeitern bedeutet, die von der Redaktion von Hrvatska Straža zur Redaktion von Hrvatski Glas gewechselt haben. Genau das Gegenteil ist der Fall. Der erste Redakteur von Hrvatski Glas, Danijel Uvanović, hat auch von Anfang 1939 bis Mitte 1940 die Redaktion von Hrvatska Straža innegehalten. Auch die anderen Redakteure von Hrvatska Straža wie Ivo Bogdan, Ivo Degrel und Ivo Lendić haben ihre Arbeit als Journalisten und Redaktionsmitglieder von Hrvatski Glas fortgesetzt. Eine wesentlich andere redaktionelle Politik der neuen Tageszeitungen war daher nicht zu erwarten gewesen. Wenn das Erzbistum Zagreb als Eigentümer der Tageszeitung beabsichtigt hatte, sich dem Einfluss der Politik zu entziehen, kann man annehmen, dass dies aus dem einfachen Grund nicht möglich war, weil es sich auf den bereits vorhandenen Kader von Redakteuren und Journalisten verlassen musste. Und dieses Personal, wie die baldige Gründung des Unabhängigen Staates Kroatien gezeigt hat, war genau das Verbindungsglied zwischen dem neuen Regime und Hrvatski Glas, das dieser Zeitung geholfen hat, auch in der neuen politischen Konstellation erscheinen zu können.

\section{Hrvatski Glas und die Gründung des Unabhängigen Staates Kroatien}

Der Unabhängige Staat Kroatien wurde am 10. April 1941 im Zuge des Angriffs von Nazi Deutschland auf das Königreich Jugoslawien ausgerufen. Da die Hrvatski Glas eine Tageszeitung war, hatte sie die Gelegenheit, als erste der katholischen Zeitungen auf die Gründung des Unabhängigen 
Staates Kroatien Bezug zu nehmen. Diese Nachricht hat die Zeitung tatsächlich auch gebracht, die Begeisterung der Bürger beschrieben und neue Vorschriften und Gesetze bekannt gemacht. ${ }^{4}$ Die nächste Ausgabe von Hrvatski Glas wurde erst am 17. April, also erst nach fünf Tagen veröffentlicht, ohne dafür einen Grund zu nennen oder sich bei der Leserschaft zu entschuldigen. Ein Einblick in die Dynamik der Auflage von anderen katholischen Zeitungen aus dieser Zeit macht deutlich, dass es eine gewisse Aussetzung der Veröffentlichungen gegeben hat. (Jareb 2016, 78) So wurde die Zagreber katholische Wochenzeitung Hrvatska straža erst am 20. April statt am 13. April sowie die katholische Wochenzeitung Hrvatska obrana (Kroatische Verteidigung) in Djakovo erst am 27. April veröffentlicht. Das gleiche ist auch mit der katholischen Wochenzeitung Nedjelja (Der Sonntag) geschehen. Da es sich um eine befehligte Aussetzung der gesamten Presse gehandelt hat, konnte man nur aus einer Randnotiz, die am 26. April 1941 in der Hrvatski List veröffentlicht wurde, erfahren, dass das staatliche Nachrichtenbüro bereits am ersten Tag seiner Gründung erlassen hat, die Auflage aller Zeitungen bis auf weiteres auszusetzen. ${ }^{5}$

Das staatliche Nachrichtenbüro (HDNU) wurde unmittelbar nach der Staatsgründung eingerichtet und hat die Aufgabe erhalten, die Veröffentlichung antikroatischer Zeitungen und Zeitschriften zu verhindern, sowie eine Reihe neuer Zeitungen ins Leben zu rufen, die den Bedürfnissen des neugegründeten Staates und seiner Regierung gerecht werden. (Jareb 2016, 107-108) Von allen anderen Tageszeitungen haben nur das Hrvatski List aus Osijek und die katholische Tageszeitung Hrvatski Glas aus Zagreb sowie die Narodne novine, die die Gesetze und offiziellen Regierungsmitteilungen veröffentlicht haben, die Erlaubnis erhalten, die Auflage fortzuführen. Elf damaligen Tageszeitungen wurden eingestellt und eine Reihe neuer Zeitungen auf die Wege gebracht.

Der Hauptgrund, warum Hrvatski Glas trotz der Tatsache, dass fast alle Tageszeitungen eingestellt wurden, weiterhin im Unabhängigen Staat

4 Vgl. »Uskrs Nezavisne Države [Das Auferstehen des Unabhängigen Staates Kroatien] « Hrvatski Glas (weiter: $H G$ ), 16. travanj 1941., 2; »Proglas novog načelnika Zagreba [Erlass des neuen Zagreber Bürgermeisters] «HG, 16. travanj 1941., 2.; »Kako je došlo do uspostave Nezavisne Države Hrvatske [Wie es zur Gründung des Unabhängigen Staates Kroatien kam?] « HG, 16. travanj 1941., 3; usw. 
Kroatien veröffentlichen konnte, liegt darin, dass die Herausgeber, Journalisten und Mitarbeiter dieser Zeitungen fast ausschließlich wichtige Posten im neuen Staat bekleidet haben. (Jareb 2016, 69-70). So zum Beispiel Ivo Bogdan, ehemaliger Herausgeber von Hrvatska Straža und Journalist von Hrvatski Glas, wurde am 10. April zum Hauptkommissar für Presse und Werbung befördert. In dieser Funktion hat er am selben Tag in Begleitung des Chefredakteurs von Hrvatski Glas, Danijel Uvanović, die Redaktionen aller Tageszeitungen besucht und sie ermahnt, seinen Befehlen Folge zu leisten. Die erste Anordnung war, die Auflage aller Zeitungen einzustellen, bis die regimetreue Zeitung Hrvatski Narod erscheinen würde. (Macut 2016, 51)

Abgesehen davon, dass er bereits Chefredakteur von Hrvatski Glas war, wurde Danijel Uvanović auch zum Kommissar in der Jutarnji List bestellt, die bald eingestellt wurde. Darüber hinaus wurde er zum Treuhänder der größten staatlichen Druckerei Tipografija d.d. ernannt. Auch andere Mitarbeiter von Hrvatski Glas wurden ebenfalls in verschiedene Posten befördert, darunter der Journalist Mladen Bošnjak als Attaché im Außenministerium, Stipe Tomičić als Redakteur der Tageszeitung Poldan und der Zeitschirft Pokret und Ivo Lendić wurde zum Angestellten der kroatischen Botschaft in Rom bestellt.

\subsection{Die katholische Tageszeitung Hrvatski Glas in Bezug auf das Ustascha-Regime}

An manchen Stellen in der kroatischen Geschichtsschreibung ist zu lesen, dass die Hrvatski Glas dem neuen Ustascha-Regime kritisch gegenüberstand und dass die Erzdiözese Zagreb aufgrund des Regierungsdrucks ihre einzige Tageszeitung schließen musste (Jareb 2016, 100; Lasić 1989, 114). Bei der Untersuchung der gesamten Auflage von Hrvatski Glas konnte man keinen einzigen Beitrag finden, der mit seiner Stimme, seiner Haltung oder jeglicher Kritik von der offiziellen politischen Richtung der UstaschaBewegung abweichen würde. Darüber hinaus hat die Haltung dieser Zeitung in Bezug auf den Antisemitismus am besten gezeigt, wie sehr die Redaktion von Hrvatski Glas mit der Politik des Regimes im Einklang war.

Die erste Probe-Ausgabe der neuen katholischen Tageszeitung wurde am 24. Januar 1941 und die erste regelmäßige Ausgabe am 29. Januar desselben Jahres veröffentlicht. Insgesamt wurden 195 Ausgaben dieser Zeitung 
aufgelegt. Bis zur Gründung des Unabhängigen Staates Kroatien, d.h. bis zum 10. April 1941, wurden 62 Ausgaben und bis zum 31. August 1941 weitere 133 Ausgaben publiziert. Der Redakteur der ersten neunzig Ausgaben war Danijel Uvanović, Physiker und Journalist, langjähriger Chefredakteur der Hrvatska straža. (Hanžek und Dadić 2011, 73-76) Nach ihm hat Ivan Cerovac nur fünf Zeitungsauflagen verantwortet. Danach wurde die Redaktion vom Priester Josip Blažina übernommen, der alle 100 weiteren Auflagen redigiert hat (Lončarević 2011, 25).

Wie aus diesem Überblick hervorgeht, hat sich die Redaktionsleitung von Hrvatski Glas mit der Machtübernahme des neuen Regimes nicht geändert. Da Danijel Uvanović die Leitung von Hrvatski Glas verlassen hat, kann sicherlich nicht in der ungelegenen Meinung gesucht werden, die die Ustascha-Behörden über ihn haben könnte, da er geradewegs von Hrvatski Glas in die Redaktion von Hrvatski Narod, offizielle Zeitung der Ustascha-Bewegung, gewechselt hat. (Švab 1997, 409) Im Jahr 1943 war er kurze Zeit Redaktionsleiter und hat folglich die Leitung der kroatischen Nachrichtenagentur Croatia übernommen.

Der Priester Josip Blažina nahm einen ähnlichen Weg wie sein Vorgänger Uvanović. Nach einer kurzen Unterbrechung durch Ivan Cerovac ${ }^{6}$ hat er Uvanović als Redaktionsleiter beerbt. Mit dem Verlassen der Redaktionsleitung bei der Hrvatski Glas war er bis Ende 1942 Redakteur der Tageszeitung Poldan (Halbtag), und im Jahre 1943 Redakteur von Novina (Zeitung). Danach hat er sich der Herausgabe humoristischer Wochenzeitschriften wie Šilo (Ahle) und Vrabac (Spatz) gewidmet. Er hat mehrere hundert satirische Beiträge in verschiedenen Zeitungen, darunter in Ustaša, der offiziellen Wochenzeitung der Ustascha-Bewegung, veröffentlicht.

Zusammenfassend kann man aufgrund der Basisdaten von den Chefredakteuren der Hrvatski Glas sowie aus der Dynamik der Zeitungsauflage und aus der Recherche des Zeitungsinhalts nicht schließen, dass ein Konflikt oder Uneinigkeit zwischen den redaktionellen und offiziellen politischen Richtlinien bestanden hat. Es wurde kein Fall des Verbots

6 Es konnten keine biographischen Daten von Ivan Cerovac gefunden werden. 
einer Zeitungsauflage noch irgendein Konflikt mit der Ustascha-Zensur protokolliert. Man wird eine zusätzliche Bestätigung dieser Feststellung nach einer detaillierten Analyse des Verhältnisses von Hrvatski Glas zum Antisemitismus im Unabhängigen Staat Kroatien erhalten.

\section{Antisemitismus in der katholischen Tageszeitung Hrvatski Glas}

Der Antisemitismus ist als Teil der offiziellen Politik der Ustascha-Bewegung im Unabhängigen Staat Kroatien vom Zeitpunkt seiner Gründung am 10. April 1941 bis zum Tag seines Untergangs am 8. Mai 1945 vorhanden (Goldstein 2001, 106). Die Intensität dieser Politik war natürlich wechselhaft, aber sie wurde nie aufgegeben und hat nie aufgehört, für diejenigen gefährlich zu sein, auf die sie sich bezogen hat, d.h. für die Juden. Die größte Intensität des Antisemitismus im Unabhängigen Staat Kroatien ist im Jahre 1941 zum Ausdruck gekommen. (Zuckermann 2011, 79-98; Živaković-Kerže 2007, 97-105)

Da der Begriff "Antisemitismus« sehr komplex und teilweise unklar ist, wird in dieser Untersuchung, die von dem deutschen Historiker Wolfgang Benz erfasste Definition von Antisemitismus verwendet (Benz 2004, 234-235). Den Begriff »Antisemitismus« bezeichnet er als jede öffentliche Herabsetzung und jede Form der Feindseligkeit gegenüber den Juden, die normalerweise im Alltag durch Vorurteile, schwarzen Humor und Gerüchte beginnt und einen fruchtbaren Boden für die Instrumentalisierung solcher Meinungen in der Politik schafft, die die Juden aus der Gesellschaft auszuschließen versucht. Der alltägliche Antisemitismus ermöglicht die Umsetzung der Verfolgung als logische und erwartete Fortsetzung der Beseitigung von Gefahr, die von Juden ausgeht. Die Benz Definition ist besonders anwendbar, um die Auswirkungen von Propaganda und Medien auf die Entstehung und Verbreitung des Antisemitismus in bestimmten Gesellschaftsbereichen zu untersuchen. Da die Hrvatski Glas eine katholische Tageszeitung war, zeigt die Untersuchung des antisemitischen Inhalts auf ihren Seiten den Umfang und das Verständnis des Antisemitismus, wie er den Lesern dargestellt wurde. 


\subsection{Quantitative Indikatoren}

Die Tageszeitung Hrvatski Glas ist eine Nachfolgezeitung der eingestellten katholischen Tageszeitung Hrvatska Straža. Da die Hrvatska Straža etwa 2.000 Abonnenten hatte, was bedeutet, dass die Auflage zahlenmäßig etwas höher war, ist davon auszugehen, dass Hrvatski Glas in einem ähnlichen Umfang gedruckt wurde. (Buturac 1989, 157) Obwohl die Auflage auf den ersten Blick nicht hoch erscheint, sollte man bedenken, dass zu jener Zeit einzelne Zeitungsexemplare von mehreren Personen gelesen wurden, insbesondere dann, wenn Institutionen, Vereine oder Klöster bestimmte Zeitungen abonniert hatten.

Zahlenmäßig lassen sich die antisemitischen Beiträge in der Hrvatski Glas folgendermaßen zusammenfassen: bis zum 10. April 1941 sind in keiner Ausgabe von Hrvatski Glas antisemitische Inhalte, Nachrichten, Berichte, Kommentare und Zeichnungen vorhanden. Nach der Gründung des Unabhängigen Staates Kroatien bis zur Schließung der Zeitung am 31. August 1941 findet man in 132 Zeitungsausgaben insgesamt 141 antisemitische Beiträge, die man in folgende Kategorien unterteilen kann:

- Antisemitische Nachrichten über Verfolgung, Beschlagnahme von Eigentum, Tragen von Schildern, verschiedene Verbote und Repressionen 60 Beiträge. Beispiele: Warnung an die Juden von Zagreb!, 7 amerikanischer Jude wegen Steuerbetrugs verurteilt, ${ }^{8}$ Bewegungseinschränkung für jüdische und orthodoxe Gläubige, ${ }^{9}$ gekennzeichnete jüdische Geschäfte in Podravina, ${ }^{10}$ Juden tragen Schilder, ${ }^{11}$ Juden betrügen Juden; ${ }^{12}$ usw.

- Kommentare und Analysen, in denen Juden für die Konspiration und Organisation der Freimaurerei, des Kommunismus, des Liberalismus und der wirtschaftlichen Ungleichheit in der Welt beschuldigt werden, kurz: über

7 »Upozorenje zagrebačkim Židovima!« HG, 17. travanj 1941., 5.

8 »Osuđen američki Židov zbog poreznih prevara« $H G, 26$. travanj 1941., 14.

9 »Ograničenje kretanja Židova i pravoslavaca« $H G$, 17. svibanj 1941., 7.

10 »Označene židovske trgovine u Podravini« $H G, 22$. svibanj 1941., 7.

11 "Židovi nose znakove« $H G, 24$. svibanj 1941., 6.

12 "Židovi varaju Židove« $H G, 11$. lipanj 1941., 8. 
die Juden als Hauptursachen des Bösen in der Welt - 73 Beiträge. Beispiele: Ein Buch über die jüdische Gefahr, ${ }^{13}$ in verschiedenen Fabriken regieren nicht mehr jüdische Kapitalisten, sondern die kroatische Ehrlichkeit!, ${ }^{14}$ die Qual des großen Lügners, ${ }^{15}$ der jüdische Plan zur Zerstörung der Deutschen, ${ }^{16}$ Zukünftiger Weltfrieden und die Juden, ${ }^{17}$ Juden, Engländer und Freimaurer - Zerstörer der Welt; ${ }^{18}$ usw.

- Antisemitische Gesetze und Vorschriften - 8 Beiträge. Beispiele: Gesetzliche Bestimmungen zu Juden, ${ }^{19}$ Gesetzliche Bestimmungen zur Rassenzugehörigkeit, ${ }^{20}$ Registrierung von Juden bei der Ustascha-Polizei, ${ }^{21}$ Juden müssen nun spezielle Kennzeichen tragen; ${ }^{22}$ usw.

\subsection{Qualitative Indikatoren - Inhaltsanalyse}

Durch die Analyse des Inhalts antisemitischer Beiträge, Berichte und Nachrichten in der Hrvatski Glas kann man die Existenz mehrerer Kategorien antijüdischer Stereotypen feststellen. Diese Stereotypen wirken sich in erster Linie negativ auf Wirtschaft, Moral und Kultur mit dem Ziel aus, der Nation, in der sie tätig waren, Schaden zuzufügen. Natürlich haben einige Stereotypen alle drei Kategorien umfasst, wie zum Beispiel, dass die Juden die Gründer und wichtige Verbreiter der kommunistischen Ideologie sind, mit der sie die Welt erobern und unter ihre Herrschaft stellen wollen. Angesichts all dieser negativen Maßnahmen ist die Forderung nach der Beseitigung der Gefahr und der Heilung dieser Krankheit sowie nach der Entfernung des jüdischen Bazillus aus dem gesunden Organismus der

13 »Knjiga o Židovskoj opasnosti« $H G$, 13. lipanj 1941., 9.

14 "U raznim tvornicama ne vladaju više židovski kapitalisti, nego hrvatsko poštenje!« HG, 20. lipanj 1941., 7 .

15 »Agonija velikog lašca« $H G, 27$. lipanj 1941., 5.

16 "Židovski plan o uništenju Nijemaca« $H G, 25$. srpanj 1941., 3.

17 "Budući svjetski mir i Židovi« $H G, 30$. srpanj 1941., 5.

18 "Židovi, Englezi i slobodni zidari - upropastitelji svijeta« $H G, 7$. kolovoz 1941., 5.

19 "Zakonska odredba o Židovima« $H G, 20$. travanj 1941., 9.

20 "Zakonska odredba o rasnoj pripadnosti« $H G$, 1. svibanj 1941., 3.

21 „Prijava Židova ustaškom redarstvu« $H G, 11$. svibanj 1941., 8.

22 "Židovi moraju od sada nositi posebne znakove« HG, 23. svibanj 1941., 5.

Edinost in dialog 75 (2020) 2: 201-220 
Nation nur der nächste logische Schritt, um die Verfolgung und Beseitigung der Juden insgesamt aus der Gesellschaft zu rechtfertigen.

\subsubsection{Juden als Verursacher der staatlichen Wirtschaftsprobleme}

Eine der sichersten und einfachsten Möglichkeiten, Hass gegen Juden im Allgemeinen zu schüren, bestand darin, ihre Rolle in der Wirtschaft eines Landes zu unterstreichen. Diese Rolle war natürlich negativ und hat aus unangemessener, unverhältnismäßiger und unmoralischer Bereicherung und Ausnutzung der Schwächen der Völker bestanden, unter denen sie tätig waren. Der Reichtum, den die einzelnen Juden erworben haben, unabhängig von der früheren Tätigkeit des Unternehmens, war a priori verdächtig.

Die erste gesetzliche Bestimmung, die Juden direkt betroffen hat und die auch in der Hrvatski Glas veröffentlicht wurde, hat sich auf die Verhinderung ihres wirtschaftlichen Einflusses und ihrer weiteren wirtschaftlichen Tätigkeit bezogen. ${ }^{23}$ So unterzeichnete der Staatschef am 18. April 1941, acht Tage nach der Staatsgründung und am dritten Tag nach seiner Rückkehr nach Zagreb, die Gesetzesvorschrift »zur Erhaltung des kroatischen Staatsbesitzes«, in der alle jüdischen Rechtsgeschäfte, die in den letzten zwei Monaten abgeschlossen wurden, für null und nichtig erklärt wurden, wenn ihr Wert 100.000 Dinar überschritten hat. Darüber hinaus sind die Bezirksgerichte bevollmächtigt, Kaufverträge in den Grundbüchern nach eigenem Ermessen aufzuheben. Diese so eindeutig formulierte Gesetzesvorschrift zeigt, dass sie die geltenden Rechtsnormen und rahmen überhaupt nicht beachtet, sondern als anscheinendes Recht zur allgemeinen Plünderung jüdischen Eigentums auf dem Gebiet des Unabhängigen Staates Kroatien gedient hat.

Diese illegale Enteignung zeigt sich am deutlichsten in der Benennung sogenannter Kommissare in den jüdischen Unternehmen, durch die die Ustascha-Behörden unmittelbar nach der Gründung des Staates eine systematische Beraubung gestartet haben. Es ist erforderlich darauf hinzuweisen, dass es hierbei nicht um die Verstaatlichung des privaten Kapitals im Allgemeinen gehandelt hat, da auf diese Weise das ganze Privateigentum

23 Vgl. "Zakonska odredba o Židovima [Gesetzliche Bestimmung über die Juden] « HG, 20. travanj 1941., 9. 
des Unternehmens in Staatseigentum übergehen würde, sondern dass die Rassenzugehörigkeit ein entscheidendes Kriterium war, um den Prozess als Arianisierung der Wirtschaft einzuleiten. (Kisić-Kolanović 1998, 429433) Alle Phasen dieser Handlung kann man auf den Seiten von Hrvatski Glas verfolgen. Ein Beispiel dazu: »In Đurđevac und Novigrad Podravski hat die Kennzeichnung von Juden und jüdischen Geschäften angefangen. Somit wurde das Erfordernis erfüllt, diese Ausbeuter vom Kreis jedes ehrlichen, humanen und besonders rein kroatischen Unternehmens zu trennen. ${ }^{24}$ Es bestand keine Notwendigkeit für weitere Erklärungen, dass die Juden Ausbeuter waren, weil dies bereits »allgemein bekannt und akzeptiert« war. Zahlreiche Nachrichten zur Verstaatlichung des jüdischen Eigentums auf den Seiten dieser katholischen Tageszeitung ${ }^{25}$ wurden durch die Veröffentlichung des entsprechenden Rechtsrahmens ${ }^{26}$ und der Kommentare begleitet, die diese Regierungsmaßnahmen gerechtfertigt haben. So hat die Hrvatski Glas die Reden von Vjekoslav Blaškov, dem Staatskommissar der Arbeitskammer, übertragen, der in der Zeit zwischen den Kriegen aktives Mitglied von katholischen Vereinen wie der Kroatischen Adlerallianz und der Großen Kreuzbruderschaft war. (Dizdar und Rupić 1997, 39) Blaškov hat seine zahlreichen öffentlichen Auftritte bei verschiedenen Arbeitertreffen benutzt, um Juden wiederholt als das wirtschaftliche Hauptproblem des kroatischen Staates hervorzuheben, sowohl im Königreich Jugoslawien als auch im Unabhängigen Staat Kroatien. »Juden waren diejenigen, die immer als Feinde der menschlichen Gesellschaft angesehen waren. In der Geschichte gab es keine Nation, unter der Juden gelebt haben, ohne ein Durcheinander verursacht zu haben. [...] Das Judentum hat unsere Kultur gefährdet. Es ist völlig anders als die arische Rasse. [...] Die Juden haben nichts in sich, was den Menschen veredelt und

24 »Označene židovske trgovine u Podravini [Jüdische Läden gekennzeichnet] «H, 22. svibanj $1941 ., 7$.

25 Beispielsweise: „Čišćenje u društvima [Säuberung in den Vereinen] « HG, 18. svibanj 1941., 11.; »Srbi i Židovi otpušteni iz gradske službe [Serben und Juden aus dem städtischen Dienst entlassen] « $H G$, 26. svibanj 1941., 6.; "Židovi u Brčkom ne mogu kupovati povrće rano u jutro [In Brcko können Juden frühmorgens kein Gemüse kaufen] « $H G, 26$. svibanj 1941., 15.; "Zabranjen rad židovskim i srpskim društvima u Požegi [Untersagt die Tätigkeit für jüdische und serbische Vereine in Pozega] $H G, 28$. svibanj 1941., 9.; "Židovi i pravoslavni označeni žuti i crveno [Juden und Orthodoxe in gelb und rot gekennzeichnet] «HG, 28. svibanj 1941., 9 .

26 "Zakonska odredba o sprječavanju prikrivanja židovskog imetka [Gesetzvorschrift zur Unterbindung der Verschleierung jüdischer Vermögen] «HG, 6. lipanj 1941., 4.; "Židovi i Židovska poduzeća obvezana su prijaviti svoje imetak [Juden und jüdische Unternehmen werden verpflichtet ihr Vermögen anzuzeigen]« $H G, 6$ lipanj 1941., 4 . 
was uns opferbereiten Ariern nahestehen würde [...]. ${ }^{27} »$ Da die Juden das wirtschaftliche Hauptproblem darstellen, ist es notwendig, sie aus der kroatischen Gesellschaft zu beseitigen. Dass man an diesem Problem intensiv gearbeitet hat, hat derselbe Staatskommissar zwei Wochen später bestätigt: 'Etliche Fabriken werden nicht mehr von jüdischen Kapitalisten geleitet, sondern von kroatischer Ehrlichkeit!' «28 Die Lösung der jüdischen Frage war in der Tat nur eine Entschuldigung für besessene und unbegründete Plünderungen.

\subsubsection{Behinderung des jüdischen Einflusses auf die kroatische Kultur}

Die jüdische Minderheit in Kroatien hat im kulturellen Bereich des sozialen Lebens wichtige Beiträge geleistet. Juden haben sich aktiv an der Schaffung und Nutzung von kulturellen Inhalten beteiligt, für die sie aufgrund ihrer wirtschaftlichen Stärke häufig Förderer und Unterstützer waren. Da diese Bedeutung bekannt war, wurde versucht, sie zu dämonisieren und sie als stimmiges Werkzeug darzustellen, mit dem die Juden die kroatische Gesellschaft beherrschen wollten. Auch die Redaktion von Hrvatski Glas schloss sich diesen Einsätzen an und hat alle Kultur- und Verlagsunternehmen unterstützt, die darauf ausgerichtet waren, den Antisemitismus als solchen zu fördern und zu verbreiten. So hat die Hrvatski Glas das Buch Trojanisches Pferd oder die Juden unter uns den Lesern empfohlen, weil das Werk die perfide Rolle der Juden weltweit offenlegt, die durch die Verbreitung des Marxismus und durch den Einfluss auf die Presse im Allgemeinen stattfindet. »Juden haben sich immer mit den Feinden des Christentums zusammengetan. In der Freimaurerei haben sie sehr schnell die wichtigsten Posten eingenommen und sie vollständig ihren Interessen unterworfen. Der Vater des Marxismus sowie die größten marxistischen Führer waren ebenso Juden. In den Demokratien haben die Juden durch Presse und Politik großen Einfluss ausgeübt. $\ll^{29}$ Freilich hat das Blatt auch die gesetzlichen Bestimmungen zum Schutz der Volks- und arischen Kultur des kroatischen Volkes bekannt gemacht: »Aufgrund ihrer Rasse ist den Juden

27 "To je borba zarade od jednog dinara na sat, protiv zarade od jedne milijarde na sat! $H G, 6$. lipanj 1941., 7.

28 » raznim tvornicama ne vladaju više židovski kapitalisti, nego vlada hrvatsko poštenje! « $H G, 20$. lipanj 1941., 7.

29 "Trojanski konj ili Židovi među nama [Trojanisches Pferd oder die Juden unter uns] HG, 29. svibanj 1941., 10 . 
verboten, an der arischen Kultur, an der Aktivität von Organisationen und Institutionen des sozialen, jugendlichen, sportlichen und kulturellen Lebens des kroatischen Volkes im Allgemeinen, insbesondere an der Literatur, dem Journalismus, an der bildenden und musikalischen Kunst, am Städtebau, an Theater und Film teilzunehmen. $\aleph^{30}$

Unter der Rubrik Kulturelle Stimme, in der die Nachrichten über das kulturelle Leben gemacht wurden, stand auch die Anzeige des antisemitischen Buches von Radovan Golubić unter dem Titel: Gibt es eine jüdische Gefahr? Die Nachricht wurde mit folgendem Kommentar begleitet: »Jeder, der das Buch liest, wird die Maßnahmen für gerechtfertigt halten, die unsere kroatische Regierung in Bezug auf die Judenfrage ergriffen hat. Jeder von uns weiß sehr gut, dass die Juden bei uns in Kroatien viel Böses getan haben und dass es höchste Zeit war, diesem Übel ein Ende zu setzen. « ${ }^{31}$

Neben den Büchern hat Hrvatski Glas auch zwei antisemitische Filme empfohlen: Jud Süß und Die Rothschilds. Das Hauptanliegen des Films Jud Süß war, die perverse und böse jüdische Natur aufzudecken. »Die Absicht des Regisseurs des kulturhistorischen Films war zu zeigen, wie die Juden ihre Umgebung zuerst in materieller Hinsicht sich selbst unterwerfen, weil das andere dann von sich aus 'weiter' geht [...] Weiterhin werden einige widerliche Taten von Oppenheimer und anderen Juden gezeigt und wie am Ende die Sache des Volkes gesiegt hat. Die Juden wurden erneut aus Stuttgart vertrieben, und Süß Oppenheimer landet hoch am Galgen. $\aleph^{32}$ Interessant war die Beschreibung der Rolle des deutschen Schauspielers Ferdinand Marian, der die Hauptfigur des Films bekleidet hat. Es wurde darauf hingewiesen, dass dieser Schauspieler regelmäßig widerliche Rollen verkörpert, wie den heuchlerischen englischen Richter Grandison oder, wie in diesem Fall, den Jud Süß.

Der Filmkritiker von Hrvatski Glas hat auch den Film Die Rothschilds empfohlen, in dem die Skrupellosigkeit eines jüdischen Bankiers gezeigt wurde.

\footnotetext{
30 "Za obranu kulture hrvatskog naroda [Zur Verteidigung der Kultur des kroatischen Volkes]« $H G, 5$. lipanj 1941., 4 .

31 »njiga o židovskoj opasnosti [Ein Buch über die jüdische Gefahr]« HG, 13. lipanj 1941., 9.

32 "Židov Suss [Film Jud Süß]« HG, 18. svibanj 1941., 14.
} 
Er hat das Gerücht verbreitet, Napoleon habe in der Schlacht bei Waterloo gesiegt, worauf die Aktienkurse an der Londoner Börse abgestürzt sind, die er gekauft und damit ein Vermögen illegal geschaffen hat. »Die Schlacht von Waterloo war nicht nur die Niederlage Napoleons, sondern sie bedeutete auch den Eintritt einer Rasse und Nation in die englische Geldmacht. Der Börsenerfolg Rothschilds bedeutet heute mehr als Napoleons Niederlage« ${ }^{33}$ hat der Filmkritiker notiert.

Es war der jüdische Einfluss auf die kroatische Kultur, der als eines der wichtigsten Werkzeuge bei der Verbreitung moralischen Verfalls angesehen wurde. »Dieses Gift ist nicht auf kroatischem Boden gewachsen. So wie der Gründer und Erfinder des bolschewistischen Giftes, Karl Marx, Jude war, waren auch die anderen 'Apotheker' hauptsächlich Juden, die dieses Gift verkauft haben. In den letzten zwanzig Jahren gab es in Kroatien Tage, an denen es gerade mit Büchern und anderem Propagandamaterial überflutet wurde, das von jüdischen Unternehmen veröffentlicht wurde. ${ }^{34}{ }^{3} \mathrm{Da}$ die Rolle der jüdischen Minderheit in der kroatischen Gesellschaft laut Hrvatski Glas einhellig schädlich und negativ war, kann man in dieser Zeitung ungeteilte Unterstützung für die Beseitigung des Problems finden.

\subsubsection{Die Lösung der Judenfrage}

Im Unabhängigen Staat Kroatien haben die Zeitungen und Zeitschriften unter dem wachsamen Auge der Zensur gestanden. Damit sollte sichergestellt werden, dass die veröffentlichten Schriften den aktuellen politischen Richtlinien des Regimes entsprachen, die offizielle Ideologie widerspiegeln oder zumindest nicht dagegen waren. Daher ist es verständlich, dass man Beiträge und Texte, die gegen die Ustascha-Regierung sprechen, nicht in den Zeitungen und Zeitschriften findet. In den katholischen Zeitschriften, die während dieser Zeit publiziert wurden, begegnet man jedoch solchen Texten, die mit ihren Themen und Auffassungen dem Evangelium gänzlich widersprechen und die als solche in den Zeitungen mit dem Adjektiv katholisch nichts zu suchen hätten. Dies gilt insbesondere für jene Beiträge, in denen die Juden und die Judenfrage thematisiert wurden. So hat die

33 »Rothschild i bitka kod Waterlooa [Die Rothschilds und die Schlacht bei Waterloo] « HG, 21. lipanj 1941., 11.; "Bogat kao Rothschild. Povodom premijere istoimenog u Zagrebu " [Reich wie Rothschilds. Anlässlich der Filmpremiere in Zagreb]« $H G, 17$. kolovoz 1941., 11. 
Redaktion von Hrvatski Glas den folgenden Text aus der in Sarajevo erscheinenden Katolički tjednik (Katholische Wochenzeitung) wiedergegeben.

"Die Bewegung zur Befreiung der Welt von den Juden ist eine Bewegung zur Wiederherstellung der Menschenwürde. Der allmächtige und weise Gott hat selber für diesen Schutz und die Bewegung gesorgt. [...] Es besteht kein Zweifel, dass jetzt nicht nur die Reihen der staatlichen Organe und Behörden, sondern auch der Zivilgesellschaften gereinigt werden, um den zerstörerischen Einfluss dieses bösen Parasiten zu verhindern, der seine zerstörerischen Fäden unsichtbar und heimlich wie Getreiderost im kroatischen Organismus verbreitet hat, um ihn zu schwächen und ihn unbemerkt und langsam zu beseitigen. [...] Eine schnelle und entschlossene chirurgische Hand sollte dieses Krebsgeschwür vollständig aus unserem nationalen Organismus entfernen $[\ldots] .{ }^{35}$

Angesichts dieser Worte ist es keineswegs überraschend, dass dem deutschen Angriff auf die UdSSR am 22. Juni 1941 mit Enthusiasmus begegnet wurde. Die Interpretation dieses Angriffs war in katholischen Kreisen mit der endgültigen Beseitigung des Kommunismus, d.h. des größten Feindes, den das Christentum jemals gehabt hat, verbunden. Der Kommentar von Hrvatski Glas lautete wie folgt:

»Katholische Auffassungen und Schriften haben ständig vor der schrecklichen Gefahr dieser schweren Infektion gewarnt. Dem übrigen europäischen Bürgertum haben jedoch die Kraft und Energie und insbesondere richtige Ansichten und geistiges Engagement gefehlt, um aus der Schläfrigkeit herauszukommen. Dem ist aber nun das Ende gekommen. Heute freuen wir uns, in einer Zeit zu leben, in dem sich dieses lügnerische jüdisch-bolschewistische Gebäude in Agonie befindet und in kurzer Zeit zu Staub und Asche zerfallen wird.« [...]»Der Kampf des großen Deutschen Reiches sowie seiner Verbündeten ist auch der Kampf des Christentums, wie das deutsche katholische Episkopat in seiner jüngsten Botschaft an seine Geistlichen unterstrichen hat. Dies sind die Kreuzzüge, die in der Geschichte notwendiger denn je waren, denn es handelt sich um den größten Feind von Menschen,

35 "Zašto gone Židove? [Warum werden Juden vertrieben?] « HG, 28. svibanj 1941., 5. 
Familie, Gesellschaft, Menschlichkeit, geistlicher Kultur, Glauben, Kirche und Gott. ${ }^{36}$

Der Kommunismus ist eine jüdische Erfindung, und Stalin ist aufgrund seiner Herkunft auch ein Jude, wurde in Hrvatski Glas weiter erklärt. ${ }^{37}$ Darüber hinaus hat der gleiche jüdische Geist die Schaffung von Kommunismus und Kapitalismus ermöglicht. Daher ist nicht verwunderlich, dass England und die Vereinigten Staaten als kapitalistische Länder Verbündete der UdSSR sind, eines kommunistischen Landes, weil die beiden Systeme von jüdischen Interessen heimlich geleitet werden. »Dieser jüdische Geist ist nicht länger etwas Äußeres, sondern ein integraler Bestandteil der englischen Kultur, etwas Inneres, so wie der jüdische Geist der innere und wesentliche Bestandteil des Bolschewismus ist. Der jüdische Geist, der in England und den Vereinigten Staaten mit Geld geherrscht und in der Sowjetunion mit roher Gewalt regiert hat, ist jetzt bedrängt und vom Aussterben bedroht. Das ist eigentlich der geheime Schlüssel, warum die Briten, die Sowjetunion und die Vereinigten Staaten sich in dieser Angelegenheit zusammengefunden haben. $\$^{38}$

In Anbetracht all dessen überrascht die folgende allgemeine Schlussfolgerung der Redaktion von Hrvatski Glas nicht: »Es kann keinen Zweifel daran bestehen, was unsere Wünsche sind: unabhängig von anderen Anliegen wollen wir in erster Linie den Untergang des Bolschewismus als System des programmierten Atheismus und der vergötterten Materie, da dieses ein System ohne Glauben, ohne Moral, ohne Kultur, ohne Menschlichkeit ist. Wenn Hitler nur dies täte, um den Bolschewismus zu liquidieren, würde er der Geschichte und der Menschlichkeit einen dauerhaften, immensen und unschätzbaren Dienst erweisen. Er hätte damit seine Leistung und sein Auftreten in der Welt gerechtfertigt. Die Welt wird ab morgen besser sein; es wird kein zerstörerisches marxistisches Gift mehr darin sein. «39

\footnotetext{
36 "Agonija velikog lašca [Todeskampf des großen Lügners] « $H G$, 27. lipanj 1941., 5.

37 "Staljinovo tamno porijetlo. Dva Georgijska autora dokazuju njegovo židovsko porijetlo po majci [Die dunkle Herkunft Stalins. Zwei georgische Autoren beweisen seine jüdische Herkunft über die Mutter.]«HG, 18. kolovoz 1941., 6 .

38 »Engleska skinula masku [England hat seine Maske abgelegt]《 $H G, 1$. srpanj 1941., 5.

39 „Boljševizam pred propašću [Bolschewismus vorm Kolpas] «HG, 8. srpanj 1941., 5; »Dosljedni junačkoj prošlosti [Vgl. In Übereinstimmung mit der heldenhaften Vergangenheit]« HG, 9. srpanj 1941., 5.
} 
Der Antisemitismus auf den Seiten von Hrvatski Glas stimmte mit anderen antisemitischen Beiträgen in den regimetreuen Medien im Unabhängigen Staat Kroatien überein, deren Ziel war, Rassenhass gegen einen Teil der Bevölkerung aufzustacheln. Da die Hrvatski Glas bereits Ende August 1941 eingestellt wurde, kann man nicht annehmen, dass sich die redaktionelle Politik gegenüber dem Antisemitismus nicht geändert hätte, nachdem die Berichte über Verfolgung und Ermordung von Juden in der NDH zu unbestreitbaren Fakten geworden waren. Auf der anderen Seite kann man beibehalten, dass der Antisemitismus in dieser Zeitung das Ergebnis einer Verknüpfung aus persönlicher Neigung und Opportunismus war, da die Herausgeber und Mitwirkenden nach der Zeitungsschließung weiterhin erfolgreich mit dem Regime zusammengearbeitet und Fortschritte in ihrem Berufsleben erzielt haben. Diese Neigung wurde sicherlich durch den Anstieg antisemitischer Haltung in den 1930er Jahren in der gesamten katholischen Presse beeinflusst, zu der auch der Sieg der Nationalsozialisten in Deutschland 1933 einen deutlichen Anstoß geleistet hat. Um jedoch alle Einflüsse auf die Entwicklung des Antisemitismus in der Zeit vor der Gründung der NDH zu identifizieren und zu klären, müssten neue Forschungsarbeiten durchgeführt werden, die über die Absichten dieses Beitrags hinausgehen.

\section{Antisemitismus von Hrvatski Glas im Kontext der katholischen Presse im Unabhängigen Staat Kroatien}

Was die gesamte katholische Presse betrifft, so wurde das Thema Antisemitismus in der kroatischen Geschichtsschreibung bisher in den folgenden Zeitschriften teilweise oder vollständig untersucht: Hrvatski Borac (Macut 2017), Krš̌ćanska obitelj (Macut 2016), Hrvatska Straža, Nedjelja und Katolički tjednik. Zahlenmäßig sind die Beiträge für Hrvatski Glas, Hrvatska Straža, Nedjelja und Katolički jednik bekannt. Wie bereits erwähnt, wurden insgesamt 141 antisemitische Beiträge in der Tageszeitung Hrvatski Glas publiziert, Im Jahre 1941 wurden in den katholischen Zeitschriften 79 antisemitische Beiträge in Hrvatska Straža, 77 in Katolički tjednik und 21 in Nedjelja veröffentlicht. Im Gegensatz zu Hrvatski Glas wurden diese Wochenzeitungen über das ganze Jahr 1941 aufgelegt. 
Beachtenswert ist der Unterschied in der Provenienz antisemitischer Nachrichten, die die oben genannten Zeitschriften veröffentlicht haben. Während die Hrvatski Glas eine gleiche Anzahl antisemitischer Nachrichten aus dem In- und Ausland brachte, hat der Katolicki tjednik aus Sarajevo die meisten antisemitischen Nachrichten aus dem Ausland publiziert. Die Hrvatska Straža hingegen hat die meisten antisemitischen Nachrichten aus dem Unabhängigen Staat Kroatien abgedruckt. Diese Verschiedenartigkeit bei der Veröffentlichung antisemitischer Beiträge spricht für die redaktionelle Freiheit, die jede Redaktion bei der Auswahl hatte. Dass es auch eine Möglichkeit gab, die Publikation antisemitischer Nachrichten zu vermeiden, hat das Fehlen von antisemitischen Beiträgen in vielen anderen katholischen Zeitschriften, die während der NDH aufgelegt wurden, gezeigt. (Macut 2016, 192-307) In der Tat hat die überwiegende Mehrheit der katholischen Zeitungen keine antisemitischen Beiträge, Kommentare und Nachrichten publiziert. Jedoch die populärsten, am weitesten verbreiteten und einflussreichsten, angeführt von der letzten katholischen Tageszeitung Hrvatski Glas, haben solche Beiträge verbreitet.

\section{Schluss}

Die letzte katholische Tageszeitung, Hrvatski Glas, die von Januar bis Ende August 1941 aufgelegt wurde, hat konsequent antisemitische Nachrichten und Berichte publiziert und antisemitische Propaganda verbreitet. So hat sich diese Zeitung aktiv an der Lösung der Judenfrage auf dem Gebiet des Unabhängigen Staates Kroatien beteiligt, was letztendlich die Beseitigung von 80 Prozent aller dort lebenden Juden mit sich gebracht hat. Die Aktivität von Hrvatski Glas hat sich in der ständigen und konsequenten Publikation aller Agenturnachrichten zu antisemitischen Gesetzen und Maßnahmen in übrigen Achsenmächten sowie aus dem Inland gezeigt. Darüber hinaus hat Hrvatski Glas in seinen redaktionellen Kommentaren die UstaschaBehörden bei ihren Bemühungen gelobt und unterstützt, die kroatische Gesellschaft vom Einfluss des »jüdischen Giftes« zu reinigen. Diese Ansichten haben mit dem Angriff des Deutschen Reiches auf die UdSSR einen besonderen Höhepunkt erreicht, als dabei der Anschein herrschte, die NS-Armee könne Sowjetrussland leicht besiegen. 
Im Zusammenhang mit durchgeführten Untersuchungen wird klar, dass es in der Geschichte der katholischen Kirche in Kroatien notwendig ist, den Anteil antisemitischer Ansichten betreffend einzubeziehen, was bisher nicht der Fall war. Hoffentlich wird diese Analyse einer der ersten Schritte in diese Richtung sein.

\section{Referenzen}

Benz, Wolfgang. 2004. Was ist Antisemitismus. Bonn: Schriftenreihe der Bundeszentrale für politische Bildung

Buturac, Josip. 1989. Katolički dnevnik Hrvatska Straža 1929-1941 [Katholische Tageszeitung Hrvatska Straža 19291941]. Croatica Christiana periodica 23: 141-200.

Goldstein, Ivo. 2001. Holokaust u Zagrebu. Zagreb: Novi Liber

Hanžek, Branko, und Žarko Dadić. 2011. Fizičar i publicist Danijel Uvanović prilog znanstvenom i političkom životopisu s bibliografijom radova [Der Physiker und Publizist Danijel Uvanović - Ein Beitrag zur wissenschaftlichen und politischen Biographie mit Bibliographie]. Časopis za suvremenu povijest 1: 73-106.

Jareb, Mario. 2016. Mediji i promidžba u Nezavisnoj Državi Hrvatskoj [Medien und Öffentlichkeitsarbeit im Unabhängigen Staat Kroatien]. Zagreb: Hrvatski institut za povijest.

Kisić Kolanović, Nada. 1998. Podržavljenje imovine Židova u NDH [Verstaatlichung des jüdischen Eigentums in der NDH]. Časopis za suvremenu povijest 3 : 429-453.
Krišto, Jure. 2004. Hrvatski katolički pokret 1903.-1945. [Katholische Bewegung in Kroatien 1903-1945]. Zagreb: Glas Koncila.

Lasić, Stanko. 1989. Miroslav Krleža $i$ Nezavisna Država Hrvatska 10. 4. 1941-8. 5. 1945. Zagreb: Globus.

Lončarević, Vladimir. 2011. Josip Blažina. Glas Koncila 35: 25.

Macut, Petar. 2017. Vukovarski Hrvatski Borac - katolički i ustaški tjednik. Scrinia Slavonica 1: 253-290.

- - -. 2016. U sjeni križa, samokresa i noža: katolički tisak u Nezavisnoj Državi Hrvatskoj [Im Schatten des Kreuzes, Colts und Messer: Die katholische Presse im Unabhängigen Staat Kroatien]. Split: Redak.

Zuckreman Itković, Boško. 2006. Funkcija protužidovske propagande zagrebačkih novina u Nezavisnoj Državi Hrvatskoj od travnja do srpnja 1941. godine [Die Rolle der antijüdischen Propaganda von Zagreber Zeitungen im Unabhängigen Staat Kroatien von April bis Juli 1941]. Časopis za suvremenu povijest 1: 79-98.

Živaković Kerže, Zlata. 2007. Podržavljenje imovine Židova u Osijeku u NDH [Verstaatlichung des jüdischen Eigentums in Osijek in der NDH]. Časopis za suvremenu povijest 1 : 97-116. 